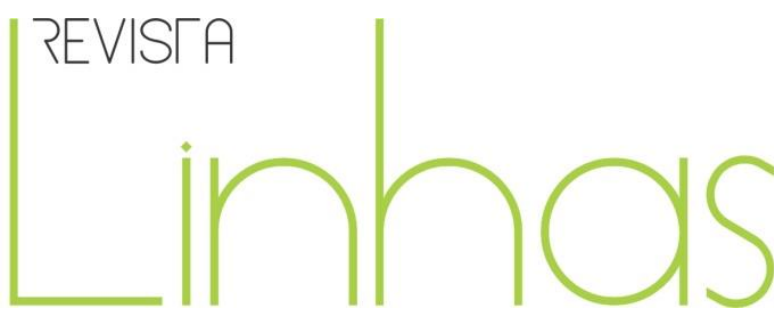

\title{
La subjetividad e intersubjetividad: un camino en la comprensión de lo cultural ${ }^{1}$
}

\section{Resumen}

Se presenta esta reflexión a partir de la pregunta ¿Por qué la subjetividad $e$ intersubjetividad se constituyen en un camino epistemológico para la comprensión de lo cultural de una realidad social que posee su propia dinámica histórica?, en la que se empleó como metodología un estudio de caso de tipo colectivo, mediante el enfoque cualitativo hermenéutico y el método narrativo. Se tiene en cuenta que es el sujeto, quien integra en su racionalidad, en su espiritualidad y en sus prácticas los contenidos culturales de una estructura social, política y económica, además, es en el acercamiento con el otro, como se desentraña el tejido social de sentidos y significados que configuran una construcción de lo cultural.

Palabras clave: Sujeto; Subjetividad; Intersubjetividad; Espiritualidad; Lo cultural.

\section{Para citar este artigo:}

OSSA, María Elisa Álvarez. La subjetividad e intersubjetividad: un camino en la comprensión de lo cultural. Revista Linhas. Florianópolis, v. 17, n. 34, p. 323-336, maio/ago. 2016.

DOI: $10.5965 / 1984723817342016323$

http://dx.doi.org/10.5965/1984723817342016323

\footnotetext{
${ }^{1}$ Este texto parte de una pregunta que orientó la investigación titulada "Construcción de cultura política democrática desde las subjetividades e intersubjetividades en organizaciones juveniles del municipio de Guacarí, Colombia: diseño de una propuesta educativa" realizada entre 2011 - 2014.
}

\author{
María Elisa Álvarez Ossa \\ Unidad Central Del Valle del \\ Cauca - UCEVA - Colômbia \\ proelisa@hotmail.com
}




\section{Subjectivity and intersubjectivity: a path to understand culture}

\begin{abstract}
This reflection arises from the question "Why subjectivity and intersubjectivity constitute an epistemological way for understanding cultural of a social reality that has its own historical dynamics?"”. It is taken in mind that is the subject subject who integrates the cultural contents of a social, political and economic structure in his rationality, spirituality and practices. Therefore, the social fabric of feelings and meanings that shape a cultural construction is unraveled through the approach to the other.
\end{abstract}

Keywords: Subject; Subjectivity; Intersubjectivity; Spirituality; Cultural.

\section{Subjetividade e intersubjetividade: um caminho na compreensão do cultural}

\begin{abstract}
Resumo
Esta reflexão surge a partir da pregunta "Porque a subjetividade e intersubjetividade constituem uma forma epistemológica para a compreensão cultural de uma realidade social que tem suas próprias dinâmicas históricas?"3, em que teve como abordagem metodológica un estudo de caso de tipo coletivo, mediante enfoque qualitativo hermenéutico e método narrativo. Considerando que é o sujeito, quem incorpora na sua racionalidade, sua espiritualidade, os conteúdos culturais de uma estrutura social, política e econômica, mais também na abordagem com o outro, como se desentranha o tecido social de sentidos que configura uma construção do cultural.
\end{abstract}

Palavras-chave: $\quad$ Sujeito; $\quad$ Subjetividade; Intersubjetividade; Espiritualidade; Cultural.

\footnotetext{
${ }^{2}$ It is a question that was reflected and answered in order to have epistemological clarity in the research entitled "Construction of democratic political culture from the subjectivities and intersubjectivities of youth organizations in the municipality of Guacarí, Colombia: design of an educational proposal" it was carried out between 2011 and 2014 with a methodological approach which corresponds to a case study of collective type, through the qualitative hermeneutic approach and narrative method.

${ }^{3}$ É uma pergunta que se reflexionou e se conseguiu dar resposta, para ter certeza epistemológica titulada "Construção de cultura política democrática desde as subjetividades e intersubjetividades em organizações juvenis de municipio de Guacarí, Colómbia: Desenho de una proposta educativa",realizada entre 2011 - 2014. Com uma abordagem metodológica que corresponde a um estudo de caso tipo coletivo, mediante o enfoque qualitativo hermenéutico e o método narrativo.
} 


\section{Introducción}

Este texto aborda inicialmente el concepto de subjetividad a partir de los planteamientos de algunos autores, se identifican algunos aspectos que son relevantes en el proceso de comprensión de la subjetividad e intersubjetividad, en el que se encuentra que en la indagación de la experiencia vital (individual y colectiva) con los actores sociales, si es posible analizar una realidad social, como también las prácticas culturales de los sujetos en un determinado contexto. La subjetividad e intersubjetividad pueden ser un camino en la comprensión de lo cultural.

La subjetividad es el modo de constituir una realidad social, en los diferentes aspectos que la integran: social, cultural y político. A la vez implica la manera de pensar, sentir, comunicar y dar sentido e intencionalidad a las formas de interactuar y convivir del sujeto en la cotidianidad en la cual se gestan procesos de interacción cultural. Es así que la subjetividad se expresa en las vivencias propias de cada individuo, como también en las construcciones colectivas generadas en la relación con el otro y lo otro (el contexto).

La reflexión sobre la subjetividad con la que se trabaja en la actualidad ha sido heredada de diferentes posturas teóricas, proveniente de las Ciencias Sociales, sin negar los aportes de otras disciplinas como la Filosofía y la Psicología. Las Ciencias Sociales permiten entender que la subjetividad no se agota ni en lo racional, ni en lo ideológico, trasciende lo cultural, lo espiritual, las estructuras organizativas de la vida social, y se instala en espacio y tiempo concreto, pero dinámico.

En el proceso de comprensión de la subjetividad desde las Ciencias Sociales, la experiencia vital de los actores sociales adquiere significatividad, es así que indagar la subjetividad se constituye en posibilidad para desentrañar y comprender una realidad social.

En este sentido, Wallerstein (1997, p. 95) propone:

Más allá del argumento obvio de que es preciso reconocer las voces de los grupos dominados (y por eso mismo en gran parte ignorados hasta ahora), está la tarea más ardua de demostrar en qué forma la incorporación de las experiencias de esos grupos, es fundamental para alcanzar un conocimiento objetivo de los procesos sociales. 
Habermas (1998, p. 22), cuando se pregunta por la comprensión de las acciones sociales, hace una seña en la racionalidad para el ejercicio de la comprensión "la comprensión de las orientaciones racionales de la acción se convierte en punto de referencia para la comprensión de todas las orientaciones de acción". Este sentido es importante en el ejercicio de interpretación y comprensión de una realidad social, pues hila las distintas relaciones del actor con el mundo, en las que están implícitas algunas racionalidades que entran a conjugarse con la racionalidad del intérprete. Para este pensador, "los distintos modelos de acción presuponen cada uno de ellos distintas relaciones del actor con el mundo; y estas relaciones con el mundo no solamente son determinantes de los aspectos de la racionalidad de la acción, sino también de la racionalidad de la interpretación de esas acciones por un intérprete" (p. 147). El acto de reflexión implica un acercamiento desde el abanico de experiencias cotidianas de los actores.

También en la filosofía foucaultiana encontramos semillas para reflexionar sobre la noción de subjetividad. En sus planteamientos, Foucault (2002) da un sentido ético a la estética de la existencia, mediante la relación del sujeto consigo mismo sin desligar el papel del mediador, las prácticas de sí, que le hacen posible a un sujeto diferente que contemple la posibilidad de transformación y libertad.

Además es necesario destacar las nuevas formas de subjetividad expresadas en la filosofía contemporánea, que conciben el sujeto no solo desde sí mismo sino en relación con el otro y lo otro como construcción cultural. Planteamientos que dan a la subjetividad un sentido de construcción y transformación desde lo social, lo cultural y lo político, en que son los sujetos como colectivos sociales quienes se funden en el crisol de las realidades y experimentan cambios que los configura en protagonistas de su historia. La subjetividad para León y Zemelman (1997, pp. 21-22):

Constituye un ángulo particular desde el cual podemos pensar la realidad social y el propio pensar que organicemos sobre dicha realidad. Implica un concepto de lo social a partir de este dinamismo particular que son los sujetos, los que en última instancia, consisten en las diferentes modalidades que pueden asumir los nucleamientos de lo colectivo como los espacios de constitución de las fuerzas capaces de determinadas construcciones sociales. 
También Zemelman plantea la relación entre las estructuras sociales y la acción colectiva, las acciones objetivas de existencia y los procesos subjetivos, entre las circunstancias y los actores sociales y el papel trascendente de los sujetos sociales en la construcción de conocimiento y sociedad. La subjetividad social es tanto individual como colectiva e implica el reconocimiento de la realidad histórica y de la capacidad de acción política.

El conocimiento social tiene que reconocer forzosamente dos pilares: el de los sujetos sociales y el del campo de la realidad en el que pueden desplazar sus capacidades de acción y de re-actuacción. Ambos [....] pueden dar cuenta de la misma potencialidad de los sujetos, o bien el que es capaz de leer la historia, no solamente como un proceso sometido a regularidades, sino además, como un campo de emergencia de los objetos que sirvan de apoyo a la capacidad de acción del hombre: esto es, la posibilidad de transformar la historia en política. (Zemelman, 1995, p. 13)

Cuando se presenta en el escenario de reflexión al sujeto social capaz de articular el pasado y el futuro en las prácticas del presente, un sujeto social que se construye teniendo conciencia prospectiva, es lo que permite trascender la idea de que se está determinado por las condiciones de un contexto histórico que lo delimita en tiempo y espacio. Se coloca en juego su capacidad y su reconocimiento como ser que no solo es histórico, sino que además construye historia. "Es así que el tiempo histórico de un sujeto tiene raíz en la pluralidad de subjetividades, cuya vinculación las dota de distintas cargas de significación según el tipo de realidades que conforman el marco vivenciable de condiciones contextuales y situacionales" (León y Zemelman, 1997, p. 60). Toda práctica social conecta pasado y futuro en su concreción presente, y dependiendo de la manera en que logre articularlas desde su subjetividad, así, se constituyen nuevas realidades personales y sociales.

La subjetividad se construye en lo cultural, y en la medida en que se dan las relaciones intersubjetivas, en planteamientos de Touraine (1997), "el deseo de ser sujeto puede transformarse en capacidad de ser un actor social a partir del sufrimiento del individuo desgarrado y de la relación entre sujetos" (p. 89), su esfuerzo por ser de manera contextualizada en tiempo y espacio, desarrollando su capacidad de interactuar 
con el otro y lo otro para transformarse y transformar. De esta manera, el sujeto es responsable no solo del desarrollo de sí mismo, sino de la dinámica cultural en permanente construcción.

Lo cultural es lo que representa la producción material e inmaterial del ser humano en un determinado contexto y devenir histórico. Se construye con el otro en un mundo compartido, que implica diversidad e identidad, donde tiene lugar el sentido del "ethos".

La cultura son muchas cosas. Está en todas partes y configura una compleja red de creencias, saberes, símbolos, costumbres, representaciones, hábitos, capacidades, valores, prácticas, instituciones, aprendizajes, conductas, lenguajes, obras artísticas, tecnologías...la cultura... se refiere a su inserción en procesos particulares de desarrollo de los individuos y de los grupos, como a los asuntos y dinámicas generales que afectan al conjunto de la sociedad. (Caride, 2005, p. 73)

En lo cultural subyacen las culturas, que se van constituyendo en el desarrollo histórico de la humanidad, mediante procesos dinámicos de cambio y transformación y se manifiestan de forma variopinta en cada contexto.

La cultura permite a cada individuo, grupo, comunidad tomar conciencia de su posición en el escenario sociohistórico [...] la cultura es de facto culturas (Carrithers, 1995), culturas con las que nos identificamos y desde las que hemos de dialogar con la intención de proveer un mundo más humano, complementario en su variedad. (Caride, 2005, pp. 74 - 75)

En la cultura subyace la fuerza de la reproducción y el control del poder hegemónicamente incorporado en un sistema social, como también la fuerza del cambio y de lo alternativo. La cultura puede y debe servir para aportar en la construcción y transformación de realidades sociales y de las prácticas culturales del sujeto político: “La cultura es un terreno estratégico y político" (Giroux, 2001, p. 43). El ímpetu de la subjetividad e intersubjetividad se manifiesta en la búsqueda de posibilidades que hace el sujeto y que se configuran en la construcción de lo cultural. 
El imperativo de la globalización y el uso desmedido de las nuevas tecnologías tienen incidencia en la confluencia de los poderes que regulan el orden mundial, que minimizan el reconocimiento de los sujetos como actores sociales e históricos, constructores de cultura.

La paradoja central de nuestra sociedad: en el momento en el que la economía se mundializa y es transformada de manera acelerada por las nuevas tecnologías, la personalidad deja de proyectarse hacia el futuro y se apoya al contrario, en el pasado o en un deseo ahistórico. El sistema y el actor ya no se encuentran en reciprocidad de perspectivas sino en oposición directa. (Touraine, 1999, p. 48)

Los cambios dados por la mundialización y los diferentes componentes que estructuran los procesos que constituyen la vida social y cultural, pueden incidir en la pérdida de sentido del sujeto político, frenando procesos de desarrollo y transformación social. Es entonces cuando se hace necesario la comprensión de la dinámica de sentidos de la cual está dotada la intersubjetividad constitutiva y constituyente del sujeto colectivo.

No es en la fragmentación del ser, sino en la capacidad integradora de dimensiones, portadora de sentidos y posibilitadora de comunicación que se llega a la comprensión de la subjetividad e intersubjetividad. En la acción comunicativa (Habermas, 1998), es que se hace posible la convivencia en medio de diferentes intereses que orientan los procesos culturales en una sociedad, donde no solo se reproduce y/o produce conocimiento sino prácticas sociales, racionalidades y sensibilidades.

Es necesario resignificar la subjetividad, rescatando los elementos espirituales que aporta la tradición filosófica de la "epimeleia heautou", la "inquietud de sí" (Foucault, 2002), sin embargo a la vez tener en cuenta los aportes de la reflexión contemporánea, en que los colectivos sociales son protagonistas de los cambios, forjando ámbitos de sentido desde el tejido vital de sus experiencias. 


\section{Sujeto - Individuo - Persona}

El concepto de sujeto pierde fuerza en la modernidad con el énfasis que se da al conocimiento, sin embargo es una categoría que tiene sentido ontológico desde la antigüedad y se ha ido transformado con la filosofía contemporánea.

En Foucault es relevante el concepto de sujeto como constructo, en que mediante la espiritualidad que es un acto de búsqueda o experiencia, por medio del cual se efectúa la catarsis por sí mismo, necesaria para tener acceso a la verdad e incluso a la felicidad y retomando desde los griegos, aclara la connotación constructiva que tiene, es decir para este autor el sujeto es construcción, es transformación.

La espiritualidad postula que la verdad nunca se da al sujeto con pleno derecho $[. .$.$] no se da por un mero acto de conocimiento, [... ]es preciso$ que el sujeto se modifique, se transforme, se desplace, se convierta, en cierta medida y hasta cierto punto, en distinto de sí mismo para tener derecho a acceso a la verdad. (Foucault, 2002, p. 33)

Es el sujeto en su condición espiritual, en la expresión de su espiritualidad, quien puede abrirse a las transformaciones y a la búsqueda de la verdad que se refiere a las respuestas que logra deducir y construir, que lo definen en su ser:

Se denomina espiritualidad, entonces, el conjunto de esas búsquedas, prácticas y experiencias que pueden ser las purificaciones, las ascesis, las renuncias, las conversiones de la mirada, las modificaciones de la existencia, etcétera, que constituyen, no para el conocimiento sino para el sujeto, para el ser mismo del sujeto, el precio a pagar por tener acceso a la verdad. (Foucault, 2002, p. 33)

Es la persona como sujeto y el sujeto entendido en su subjetividad quien puede reconocerse como creador de sentido, de intercambio y de relaciones socioculturales intersubjetivas. En la reflexión genealógica de sujeto, Foucault, al respecto en su indagación histórica sobre sujeto y verdad ve necesario tener en cuenta como punto de 
partida la noción griega "epimeleia heautou 'la inquietud de sí” (Foucault, 2002, p. 17), que significa ocuparse o preocuparse de sí mismo. Se define como:

Una actitud general, una manera determinada de considerar las cosas, de estar en el mundo, realizar acciones, tener relaciones con el prójimo, [...] es una actitud: con respecto a sí mismo, con respecto a los otros, con respecto al mundo [...]. Es también una manera determinada de atención, de mirada [...] implica cierta manera de prestar atención a lo que se piensa y lo que sucede en el pensamiento. (Foucault, 2002, p. 28)

Esta noción designa el cuidado hacia uno mismo sin descuidar la relación con los otros, contiene prácticas de transformación del ser como sujeto, y surge en los textos platónicos de los diálogos con Alcibíades y las reflexiones socráticas. Sin embargo, hay datación de prácticas ritualizadas, sobre la transformación y el cuidado de sí en la Grecia Arcaica (ritos de purificación, técnicas de concentración del alma, técnica de la retirada, práctica de la resistencia, preparación purificadora para el sueño, examen pitagórico de conciencia), la espiritualidad de la cultura oriental es enriquecedora, por sus experiencias en este sentido. Cuanto hay por contar de América al respecto, de las prácticas ancestrales y que algunas de ellas se conservan aún, otras se han desfigurado perdiendo el sentido y el significado que tenían en sus orígenes, quedando reducido al fetiche.

En la subjetividad del ser humano, la espiritualidad es un componente que se constituye en el proceso catártico del sujeto. La espiritualidad da cuenta del ser intangible y trascendental, de lo que acontece en el interior del ser humano, que tiene que ver con sus pensamientos, sentimientos, emociones, sensaciones, que movilizan su voluntad, su manera de interpretar, dar sentido y proyectar el mundo en que se vive. Pero también es lo que le permite imaginar una realidad, cuando se impregna el espíritu de libertad, sensibilidad, creatividad y utopía.

El arte, la religión, el deporte, la educación, además de ser componentes culturales, son expresiones de la espiritualidad porque mediante ellos el sujeto expresa y potencia su ser, por tanto se deduce su utilidad en los procesos transformadores. Por ejemplo, para hacer referencia solo a uno: El arte, en sus diversas expresiones, canaliza la energía espiritual y libera lo humano del ser. 
Los hombres que actúan y hablan necesitan la ayuda del homo faber en su más elevada capacidad, esto es, la ayuda del artista, de poetas e historiógrafos, de constructores de monumentos o de escritores, ya que sin ellos el único producto de su actividad, la historia que establecen y cuentan, no sobreviviría. (Arendt, 2005, p. 195)

Pensar el sujeto, implica pensarlo como persona, como individuo, es decir, un sujeto concreto que representa una unidad biológica y espiritual como totalidad cuerpo y espíritu, sin negar su condición social y cultural. El cuerpo expresa nuestra condición física, ocupa un lugar y tiempo en el mundo "el cuerpo es lo sensible, lo perceptible, lo voluptuoso, el principio del orden y el caos, la única forma aprehensible y controlable, ya que el pensamiento puede huir, traspasar todas las fronteras, burlar la represión" (Botero, 1998, p. 119). El espíritu es lo inmaterial, lo anímico, representa nuestros sentimientos, pensamientos, nuestra voluntad, nuestro modo de ser. Posibilita las experiencias vitales, la expresión de nuestra sensibilidad y también las capacidades de actitud y de conocimiento.

El hombre en tanto que persona, ¿no es el hombre psicofísico? De hecho es, en efecto, el hombre que se sabe en el mundo con soma y alma, que trabaja en el espacio y que trabaja con sus manos en tanto que artesano o de cualquier modo con su soma, que batallando en el combate también batalla somáticamente y, naturalmente, es co-consciente sin cesar de su soma, y que por medio de él actúa en su mundo externo o experimenta en él contacto, oposición, heridas. (Husserl, 1991, p. 310)

La persona siempre se halla en un cuerpo, constituida por un espíritu y en relación con otros y en unas condiciones históricas concretas. No es la persona como individuo o el individuo como tal, sino el sujeto el que logra articular y constituir conscientemente la unidad integradora: cuerpo y espíritu, ser colectivo y ser singular.

De acuerdo al pensamiento de Arendt (2005), la vida humana constituye la vida activa y la vida espiritual:

La vida activa la conforman tres actividades básicas que el ser humano realiza desde su nacimiento hasta que muere: labor, trabajo y acción. La labor es lo que se hace para procurarse la sobrevivencia, como un ser que hace parte de la naturaleza; el trabajo, 
mediante este adapta y transforma la naturaleza en la construcción de un mundo humano y la acción, es política, es lo que representa la pluralidad de su ser; es lo que implica vivir, construir y transformar con otros en la máxima expresión creativa de la libertad y la posibilidad que tiene para humanizar cada vez más el mundo, mediante la apropiación de normas, acuerdos y el perdón entre personas con lógicas diferentes. Es lo que se logra en la comprensión de la compleja indeterminación de la acción humana, para reconocer los hechos que no pueden cambiarse y la reconciliación en la posibilidad de volver a empezar, dejando siempre un camino iniciado que conduce a la grandeza de lo humano.

En términos de Arendt (2005), la vida espiritual habita en el interior del ser humano, mediante su dimensión intangible que se expresa en el pensamiento, la voluntad y el juicio, es decir un mundo configurado en dos, uno que se expresa en el exterior compartiendo con los otros y un mundo interior en la singularidad e intimidad de cada quien, pero que se complementan y se representan. Es en la vida espiritual, en la manera de reflexionar su realidad, de buscar alternativas y tomar decisiones, en que el sujeto puede encontrarse consigo mismo, con sus propósitos, sueños y acciones de la vida activa. En un mundo compartido, que hace que el sujeto se reconozca en la relación dialéctica de "el entre" (Arendt, 1997, p. 46).

La edificación de la intersubjetividad se gesta en el sentido plural del sujeto, en un espacio colectivo, social, político y cultural cuando éste entra en relación con otros, para desatar obstáculos, temores y abrir puertas al variopinto de posibilidades.

Es importante reconocer la trascendencia que aporta la subjetividad a la trayectoria conceptual de sujeto. "No se trata por lo tanto, de negar la historia ni de desdecirse de la individualidad, subjetividad [... ] sino de reformarla y completarla a partir de una potenciación del concepto de persona y del carácter relacional de la identidad humana" (Estrada Díaz, 1998, p. 35).

En la reflexión de la subjetividad es importante la comprensión del sujeto como ser colectivo y singular, porque estas dimensiones no se excluyen, pero se complementan. Como ser singular es la expresión de las experiencias personales vividas por el sujeto. Como ser colectivo es portador de relaciones interpersonales, institucionales, culturales, políticas, etc. Se entiende lo colectivo como aquello que no sólo representa lo público que es de todos, sino que es lo que se construye en la 
reflexión, en el diálogo y se transforma entre todos en la praxis "es decir, la acción (praxis) y el discurso (lexis), de los que surge la esfera de los asuntos humanos" (Arendt, 2005, p. 52).

Dado el debate que hay sobre el sujeto, si se entiende como individualidad refiriéndose a la persona o como subjetividad que es una noción que integra lo individual y lo colectivo, para lograr su reconocimiento. Es el sujeto entendido en su subjetividad, quien logra las transformaciones de sí mismo, como también la apropiación de los contenidos culturales de la tradición de su entorno, con conciencia ética e histórica y los procesos de interacción social e interpretación en un mundo intersubjetivo, lingüísticamente mediado e históricamente contextualizado.

Se encuentran sentencias en Touraine (1997, p. 66) para explicar que el sujeto también es: "el deseo del individuo de ser un actor”, un "creador de sentido y de cambio, e igualmente de relaciones sociales e instituciones políticas" (p. 67), "no es un alma presente en el cuerpo o el espíritu de los individuos, sino la búsqueda de su propia historia" (p. 67).

Touraine (1997) presenta un sujeto histórico y socioculturalmente contextualizado, consciente de los efectos de la sociedad en que vive y de la necesidad de transformar su propia realidad:

Un sujeto que no es una simple forma de la razón. Sólo existe al movilizar el cálculo y la técnica del mismo modo que la memoria y la solidaridad, y sobre todo al combatir, indignarse, esperar, inscribir su libertad personal en las batallas sociales y las liberaciones culturales. El sujeto más aún que razón es libertad, liberación y rechazo. (p. 67)

La complejidad del sujeto se consolidada desde la cotidianidad, en la configuración de la identidad cultural y en su participación como actor social y político: "La idea de sujeto es indispensable si se quieren descubrir las condiciones de la comunicación intercultural y la democracia; y en ésta perspectiva adquiere una significación política” (Touraine, 1997, p. 68). 
Esta postura encuentra así la manera de comprender la subjetividad tanto del sujeto persona, como de los grupos sociales en los cuales se gesta una red de interacciones, que expresan la forma que tienen de ver el mundo y de plasmar sus prácticas y discursos en la vida cotidiana. En la sociedad contemporánea se privilegia al sujeto colectivo y se entiende el mundo como una realidad intersubjetiva.

La subjetividad permite la comprensión de los fenómenos sociales como procesos de construcción de sentido y es a partir de la trama intersubjetiva en el tejido social que se forman los significados de la acción social como práctica cultural, desde el mundo cotidiano de la vida. La intersubjetividad permite adentrase al campo de las interacciones sociales en que las personas dan significado a todo lo que tiene sentido en el mundo cotidiano, y es el lenguaje el mecanismo mediador en las tensiones y relaciones de poder que caracterizan los procesos de construcción de cultura. La comprensión e interpretación con el otro, constituye la verdadera comprensión de la realidad.

\section{Referencias}

ARENDT, Hannah. (1997). ¿Qué es política? Traducido por Rosa Sala Carbó. Barcelona: Ediciones Paidós.

ARENDT, Hannah. (2005). La condición humana. Barcelona, España: Paidós.

BOTERO, Darío. (1998). El poder de la filosofía y la filosofía del poder I. Santa Fe de Bogotá, Colombia: Universidad Nacional de Colombia, UNIBIBLOS.

CARIDE, José Antonio. (2005). La animación sociocultural y el desarrollo comunitario como educación social. Revista de Educación, núm. 336. Universidad de Santiago de 
Compostela. Consultado el 2 de octubre de 2012, disponible en:

<http://www.mecd.gob.es/dctm/revista-de-

educacion/articulosre336/re33605.pdf?documentld=0901e72b81248652>.

ESTRADA, José Antonio (1998). Identidad y reconocimiento del otro en una sociedad mestiza. México: Universidad Iberoamericana.

FOUCAULT, Michel. (2002). La hermenéutica del sujeto. Buenos Aires, Argentina: Fondo de Cultura Económica.

GIROUX, Henry. (2001). Cultura, política y práctica educativa. Barcelona, España:

Editorial Graó.

HABERMAS, Jürgen (1988). Teoría de la acción comunicativa I. Racionalidad de la acción y racionalización social. España: Taurus.

HUSSERL, Edmund. (1991). La crisis de las ciencias europeas. Barcelona, España: Crítica.

LEÓN, Emma y Zemelman, Hugo. (1997). Subjetividad: umbrales del pensamiento social. España: Anthropos Editorial.

TOURAINE, Alain. (1997). Podremos vivir juntos. México: Fondo de Cultura económica.

TOURAINE, Alain. (1999). Critica a la modernidad. México: Fondo de Cultura Económica.

WALLERSTEIN, Immanuel. (1997). Abrir las Ciencias Sociales. Comisión Gulbenkian para la reestructuración de las Ciencias Sociales. México: Editorial Siglo XXI.

ZEMELMAN, Hugo. (1995). Determinismos y alternativas en las Ciencias Sociales de

América Latina. México: UNAM Universidad Nacional Autónoma de México. 